\title{
Carbon Dioxide as Cushion Gas for Natural Gas Storage
}

\author{
Curtis M. Oldenburg \\ Earth Sciences Division 90-1116 \\ Lawrence Berkeley National Laboratory \\ Berkeley CA 94720
}

July 9, 2002 


\begin{abstract}
Natural gas storage is used to smooth the natural gas supply to meet high peak demand. In natural gas storage, the working gas (methane) is injected and produced seasonally while a cushion gas that is not extracted is used to provide pressure support. In the case of depleted gas reservoirs being used for gas storage, the cushion gas is commonly leftover native gas (methane). Another approach is to produce most of the methane from the reservoir since it can be sold for profit and inject a cheap inert gas for use as the cushion gas. Carbon dioxide injection during carbon sequestration with enhanced gas recovery can be carried out to produce the methane while simultaneously filling the reservoir with carbon dioxide. Carbon dioxide undergoes a large change in density near its critical pressure, an advantageous feature if used as a cushion gas. Furthermore, the injection of carbon dioxide into the ground may in the future be economically favorable through carbon credits or tax advantages offerred to encourage carbon sequestration. Reservoir simulations of methane injection into a model gas storage reservoir with carbon dioxide as cushion gas demonstrate that $30 \%$ more methane can be stored relative to a native gas cushion. Limiting the rate of mixing between methane and carbon dioxide through careful reservoir selection and operations will be critical to the use of carbon dioxide as a cushion gas.
\end{abstract}


Introduction

Underground natural gas storage is relied upon to smooth the natural gas supply to meet high peak gas demands (e.g., Katz and Tek, 1981). The key to smoothing the supply is to be able to store during periods of low demand large quantities of gas that can be produced quickly to meet peak demand. To this end, excess natural gas (methane) delivered by pipelines to metropolitan areas is injected into large underground reservoirs. These are most commonly depleted natural gas reservoirs, but can also be aquifers and abandoned caverns produced by solution mining. When demand for gas exceeds supply, for example during cold weather when household heating peaks or during hot weather when large amounts of electricity must be generated for air conditioning, gas is withdrawn from the gas storage reservoir to supplement the pipeline supply and meet the peak demand. When demand for natural gas is low, gas is taken from the pipeline and injected into the gas storage reservoir.

A cross-section schematic of an idealized gas storage reservoir is shown in Figure 1 where the working gas is methane $\left(\mathrm{CH}_{4}\right)$ from the pipeline. Critical to the operation of gas storage reservoirs is the use of a cushion gas, i.e., a gas that compresses and expands as the working gas is injected or withdrawn but which is itself not produced. In the U.S., there are 415 underground natural gas storage sites, of which 348 are in depleted gas reservoirs, with total working gas capacity of $3900 \mathrm{Bcf}\left(7.4 \times 10^{10} \mathrm{~kg}\right)$ of $\mathrm{CH}_{4}$ of which $86 \%$ is in depleted gas reservoirs (Tobin and Thompson, 2001). As such, the cushion gas in the U.S. is most commonly the native gas left over after the reservoir was depleted. However, inert cushion gases such as nitrogen $\left(\mathrm{N}_{2}\right)$ that are injected specifically for use 
as cushion gas have been used successfully in Europe (Laille et al., 1986; 1988; Misra et al., 1988). The advantage of using an inert gas cushion is that more of the existing native gas can be sold to generate revenue in the case of depleted gas reservoirs, and the operator will not have to buy expensive methane to use as a cushion in the case of aquifer and solution mining cavern storage reservoirs. Although the use of inert cushion gases in the U.S. has been considered (e.g., Walker and Huff, 1964; U.S. DOE, 1980), they are not used at this time in North America.

As the working gas is injected against the cushion gas, pressure in the reservoir increases. Care must be taken not to overpressurize the gas reservoir due to the potential for leakage and for compromising the integrity of the formation cap if the reservoir is over pressurized. Similarly, as gas is withdrawn and the pressure becomes low, there is a point when it is no longer economically feasible to produce gas. As indicated by the name "cushion," compressibility is the key property of cushion gases. Because all gases are compressible, just about any gas can be used as a cushion gas. However, the efficiency of gas storage operations can be increased if the cushion gas has greater effective compressibility.

The purpose of this paper is to discuss the physical properties of carbon dioxide $\left(\mathrm{CO}_{2}\right)$ and $\mathrm{CH}_{4}$ and show by way of numerical simulations that $\mathrm{CO}_{2}$ may be a good choice for a cushion gas because of its high effective compressibility near its critical pressure. There may also be economic incentive for using $\mathrm{CO}_{2}$ through carbon credits and tax advantages created to encourage carbon sequestration. Gas storage with $\mathrm{CO}_{2}$ as cushion gas may be a logical choice for further use of gas reservoirs that have been filled 
with $\mathrm{CO}_{2}$ during carbon sequestration with enhanced gas recovery (CSEGR) (e.g., Oldenburg et al., 2001).

Physical Properties of $\mathrm{CO}_{2}$ and $\mathrm{CH}_{4}$

The density of $\mathrm{CO}_{2}$ changes drastically around its critical point of $31.1{ }^{\circ} \mathrm{C}$ and 73.8 bars. Because of the geothermal gradient $\left(\sim 25^{\circ} \mathrm{C} / \mathrm{km}\right.$ depth $)$ and typical depth of gas storage reservoirs, $\mathrm{CO}_{2}$ will normally be supercritical by virtue of temperature, and may be supercritical in terms of pressure depending on the depth and stage in the annual storage cycle (Figure 2). The nonideality of real gases can be expressed by the compressibility factor, $Z$, where

$$
Z=\frac{P V}{n R T}
$$

and where $Z=1.0$ for ideal gases, $P$ is pressure $(\mathrm{Pa}), V$ is volume $\left(\mathrm{m}^{3}\right), n$ is moles, $R$ is the universal gas constant $\left(\mathrm{J} \mathrm{mol}^{-1} \mathrm{~K}^{-1}\right)$, and $T$ is temperature $(\mathrm{K})$. Shown in Figure 3 are real gas density $(\rho)$ and $Z$ of various $\mathrm{CO}_{2}-\mathrm{CH}_{4}$ mixtures as a function of pressure at $40{ }^{\circ} \mathrm{C}$. Note from the figure that for pure $\mathrm{CH}_{4} Z$ varies from 1.0 to approximately 0.85 , while $Z$ for $\mathrm{CO}_{2}$ varies from 1.0 to less than 0.3. As shown in Figure 3, when the pressure changes from 60 to 130 bars, the density of pure $\mathrm{CO}_{2}$ increases by a factor of five, whereas pure $\mathrm{CH}_{4}$ density increases by just over a factor of two. If $\mathrm{CO}_{2}$ were used as a cushion gas within the pressure range of 60-130 bars, it would allow significantly larger quantities of working gas to be injected with less increase in pressure relative to using a cushion gas consisting of native gas or inert gas (e.g., nitrogen, $\mathrm{N}_{2}$ ). Furthermore, when the working gas is withdrawn and the reservoir pressure decreases, there will be a 
corresponding larger gas drive due to the rapid decrease in density (i.e., increase in volume) of the $\mathrm{CO}_{2}$ cushion gas.

Figure 4 shows density and viscosity at various pressures as a function of composition at $40{ }^{\circ} \mathrm{C}$. Although the density of supercritical $\mathrm{CO}_{2}$ approaches that of liquid water, the viscosity is always gas-like, i.e., of order $10^{-5} \mathrm{~Pa}$ s. The relative mobility of the two gases will be controlled by the term

$$
M=\frac{k_{r}}{\mu}
$$

where $M$ is the mobility ratio, $k_{r}$ is gas relative permeability, and $\mu$ is gas viscosity. As can be seen in Figure 4, the mobility of $\mathrm{CH}_{4}$ is larger than the mobility of $\mathrm{CO}_{2}$ due to the lower viscosity of $\mathrm{CH}_{4}$. This will tend to make the interface between $\mathrm{CH}_{4}$ and $\mathrm{CO}_{2}$ unstable as working gas is injected against the $\mathrm{CO}_{2}$ cushion. However, the opposite situation will arise during the production cycle, as relatively viscous $\mathrm{CO}_{2}$ pushes against $\mathrm{CH}_{4}$. The coefficient multiplying the pressure gradient to give the mass flux of gas in a porous medium is $\rho M k$, where $k$ is the permeability of the medium. Note from Figure 4 that variations in the density and viscosity of the two gases and their mixtures are strongly correlated. This correlation will make the flow term $\rho M k$ relatively constant as a function of pressure for the two gases. The compensating effects of density and viscosity imply that the displacement processes between the two gases will not change significantly as pressure changes.

\section{Modeling Approach}

Because $\mathrm{CO}_{2}$ has not yet been used as a cushion gas for gas storage, the analysis approach used here is numerical simulation in a generic storage reservoir. The purpose 
of this approach is to demonstrate generally the main effect of the large increase in density of $\mathrm{CO}_{2}$ around the critical region and its role in increasing storage capacity. Results presented below are calculated using EOS7C, a module of the integral finite difference TOUGH2 code (Pruess et al., 1999) that considers multiphase and multicomponent flow and transport of water, brine, $\mathrm{CO}_{2}$, gas tracer, $\mathrm{CH}_{4}$ and heat in subsurface systems. EOS7C has been used previously for carbon sequestration studies (Oldenburg and Benson, 2002).

The model system is a two-dimensional slice of a $2 \mathrm{~km} \mathrm{x} 4 \mathrm{~km}\left(1.5 \mathrm{mi}^{2}\right)$ reservoir typical of depleted gas reservoirs in the unconsolidated sediments of the California San Joaquin-Sacramento River Delta area. Properties of the model reservoir are shown in Table 1. The model reservoir as shown in Figure 5 is $22 \mathrm{~m}$ thick by $1000 \mathrm{~m}$ wide by 4 $\mathrm{km}$ long with a single injection and production well and models one-half (assuming mirrorplane symmetry) of a $2 \mathrm{~km} \mathrm{x} 4 \mathrm{~km}$ reservoir. The domain is discretized into 2200 uniform gridblocks (11 by 200 gridblocks in $Z$ - and $Y$-directions, respectively) and injection and production occur on the left-hand side at $Z=-3 \mathrm{~m}$. All of the boundaries are closed, and the initial condition is gas-static at approximately 60 bars with residual water saturation of approximately 0.26 . Depending on the case studied, the reservoir is filled initially with either $\mathrm{CO}_{2}$ or native $\mathrm{CH}_{4}$ cushion gas at 60 bars. This scenario does not consider the replacement of the native gas by the cushion gas, although this process can be part of CSEGR (e.g., Oldenburg et al., 2001; Oldenburg and Benson, 2002), where $\mathrm{CO}_{2}$ injection is used for enhanced gas recovery, and natural gas storage could be carried out as a another beneficial use of the reservoir. With porosity of 0.30 and residual liquid saturation of 0.26 , this half-size reservoir could hold $1.4 \times 10^{9} \mathrm{~kg}(89 \mathrm{Bcf}) \mathrm{of} \mathrm{CH}_{4}$ at 40 
${ }^{\circ} \mathrm{C}$ and 100 bar. Assuming the storage reservoir receives through the injection/production well $1.14 \times 10^{9} \mathrm{~kg}(60 \mathrm{Bcf})$ of $\mathrm{CH}_{4}$ over a six-month storage period, the constant $\mathrm{CH}_{4}$ injection rate is $73.5 \mathrm{~kg} \mathrm{~s}^{-1}\left(330 \mathrm{MMcf}^{-1} \mathrm{y}^{-1}\right)$. All simulations are isothermal at $\mathrm{T}=40$ ${ }^{\circ} \mathrm{C}$.

Table 1. Properties of the model gas storage reservoir.

\begin{tabular}{|l|l|l|}
\hline Property & Value & Units \\
\hline Reservoir area (X-, Y-direction) & $4000 \times 1000\left(1.5 \mathrm{mi}^{2}\right)$ & $\mathrm{m}^{2}$ \\
\hline Reservoir thickness (Z-direction) & 22 & $\mathrm{~m}$ \\
\hline Porosity & 0.30 & - \\
\hline Permeability (isotropic) & $1.0 \times 10^{-12}$ & $\mathrm{~m}^{2}$ \\
\hline Gas relative permeability & Van Genuchten-Mualem & \\
& (Mualem $(1976)$, van & \\
& Genuchten $(1980))$. &,,,---- \\
$m, S_{l l}, S_{l s}, S_{g r}$ & $0.2,0.27,1,0.01$ & - \\
Liquid is immobile & $S_{l} \approx 0.26<S_{l r}$ & $\mathrm{~m}^{2} \mathrm{~s}^{-1}, \mathrm{~m}^{2} \mathrm{~s}^{-1}$ \\
\hline Molecular diffusivity gas, liquid & $1.0 \times 10^{-6}, 1.0 \times 10^{-10}$ & ${ }^{-1} \mathrm{C}^{-10}$ \\
\hline Temperature & 40 & $\mathrm{bars}^{-1}$ \\
\hline Initial pressure & 60 & $\mathrm{~kg} \mathrm{~s}^{-1}$ \\
\hline $\mathrm{CH}_{4}$ injection rate & 73.5 & \multicolumn{2}{|l}{} \\
\hline
\end{tabular}

Results

Shown in Figures 6 and 7 are simulated gas composition and density at three times $\left(30,90,180\right.$ days) during the injection of $\mathrm{CH}_{4}$ into the storage reservoir. As the pressure increases through the critical pressure, $\mathrm{CO}_{2}$ undergoes its large compression and occupies a smaller and smaller volume. The final pressure after six months is approximately 114 bars. As shown, the strong density contrast and shallow injection interval lead to $\mathrm{CH}_{4}$ overriding the $\mathrm{CO}_{2}$ cushion to some degree. This effect is large in the thin reservoir ( $22 \mathrm{~m}$ thick) considered here, but would be much less significant in a 
thicker (vertically oriented) reservoir where the primary direction of displacement of the cushion would be up-and-down rather than side-to-side.

The interface between the two gases shows the effects of mixing due to molecular diffusion and numerical dispersion. Most of the mixing in the simulations is from numerical dispersion due to space discretization, which for a rectangular grid and full upstream weighting is approximately one-half the grid spacing multiplied by the gas velocity. For these simulations, the numerical dispersion is on the order $10^{-4} \mathrm{~m}^{2} \mathrm{~s}^{-1}(5$ $\mathrm{m} / 2 \times 700 \mathrm{~m} / 6 \mathrm{mo}$.$) . This value of numerical dispersion is approximately two orders of$ magnitude larger than molecular diffusion, creating an artificially wide mixed zone for the conditions specified.

Shown in Figure 8 are pressure evolutions for the $\mathrm{CO}_{2}$ cushion gas case along with the cases of a native gas cushion with original injection rate and with reduced injection rate. As shown, the pressure increases more for the native gas cushion. By reducing the injection rate to $70 \%$ of the original rate, and correspondingly storing $70 \%$ as much gas, the pressure evolution curve for a case with a native gas cushion approximately matches the $\mathrm{CO}_{2}$ gas cushion curve. This figure shows the fundamental advantage of the $\mathrm{CO}_{2}$ gas cushion, namely the ability of the system to store more gas than if a native gas cushion is used.

Shown in Figure 9 are $\mathrm{CO}_{2}$ mass fraction and gas density after ten months (after four months of production from the gas storage reservoir at the same rate as the original injection). Note that at this time, $\mathrm{CO}_{2}$ is upconing and impure $\mathrm{CH}_{4}$ would be produced if more production were to occur at this high rate. Such upconing and gravity override discussed above would be greatly reduced in a reservoir with greater thickness, where the 
cushion gas could be emplaced into the bottom of the reservoir and working gas injected and produced from the top. Nevertheless, this simulation demonstrates that even for the case of a thin reservoir, a large fraction of the working gas can be recovered from a storage reservoir with a $\mathrm{CO}_{2}$ gas cushion prior to $\mathrm{CO}_{2}$ breakthrough. More favorable geometry and reduced production rate would allow more pure working gas to be produced.

Discussion and Conclusions

Simulations of gas storage with $\mathrm{CO}_{2}$ cushion gas demonstrate that the density change of $\mathrm{CO}_{2}$ around the critical pressure can be exploited as a way of increasing the storage capacity of a gas storage reservoir. This effect arises because of the large decrease in $\mathrm{Z}$ value for $\mathrm{CO}_{2}$ in the pressure range from 60 to 100 bars at temperatures near $40{ }^{\circ} \mathrm{C}$. As the reservoir temperature increases beyond $40{ }^{\circ} \mathrm{C}$, the $\mathrm{Z}$ value of $\mathrm{CO}_{2}$ is larger and the advantage for gas storage diminishes.

The central issue in the use of $\mathrm{CO}_{2}$ as a cushion gas is the extent to which working gas will mix with $\mathrm{CO}_{2}$ and reduce the value of the working gas. Experimental studies have demonstrated that diffusion and dispersion processes are the same for supercritical fluids as for normal gases and liquids (Yu et al., 1999), so there should be no unexpected penalty at supercritical conditions in this regard. Recent experimental results focused on CSEGR show limited mixing for $\mathrm{CH}_{4}$ displaced by $\mathrm{CO}_{2}$ in carbonate rock cores (Mamora and Seo, 2002). Inert (e.g., $\mathrm{N}_{2}$ ) cushion gases are used with acceptable degrees of mixing in France in aquifer gas storage projects (Carriére et al., 1985).

Furthermore, the higher density and viscosity of $\mathrm{CO}_{2}$ relative to $\mathrm{CH}_{4}$ should further limit 
mixing of the two gases (Oldenburg and Benson, 2002). In the simulations presented here, the reservoir is relatively thin $(22 \mathrm{~m})$ and the gas flow is predominantly horizontal. This leads to gravity override and a broadening of the interfacial area between the gases and correspondingly more mixing. In gas reservoirs with a large vertical extent relative to lateral, the density effect of $\mathrm{CO}_{2}$ could be exploited by placing the $\mathrm{CO}_{2}$ deep in the reservoir and injecting and producing working gas from near the top. In the actual gas storage reservoir, hydrodynamic dispersion will occur which will also lead to mixing, although the degree to which reservoir gases mix is subject to considerable variability depending on reservoir geometry, anisotropy, heterogeneity, fracturing, and other properties. In short, careful reservoir selection and injection and production strategies can be developed that will limit gas mixing in particular gas storage reservoirs under consideration for injection of $\mathrm{CO}_{2}$ as a cushion gas. But clearly the extent and rate of gas mixing in the subsurface is uncertain and needs to be investigated further.

A second reason for concern about gas mixing is the change in density associated with mixing. In particular, when supercritical $\mathrm{CO}_{2}$ mixes with even a small amount of $\mathrm{CH}_{4}$, the gas density decreases strongly (Figure 3 ) which will lead to pressurization at constant volume. Thus pressurization of the reservoir simply due to gas mixing is possible, and this effect offsets the advantage of using $\mathrm{CO}_{2}$, namely that of small $Z$ value. This points out again the importance of understanding gas mixing in the subsurface, as well as the potential use of monitoring reservoir pressure as a means of assessing mixing. In conclusion, the properties of $\mathrm{CO}_{2}$ make it a good candidate for use as a cushion gas. However, the same mixing issues that arise in the use of other inert cushion gases will arise with the use of $\mathrm{CO}_{2}$, and thorough analyses of suitability (e.g., Misra et al., 
1988) will have to be carried out before $\mathrm{CO}_{2}$ can be proposed with confidence for use in any particular gas storage reservoir. If it is determined that $\mathrm{CO}_{2}$ would be a suitable cushion gas in a particular project, then additional benefits such as carbon sequestration credits can be considered in the final decision. The opportunity to use $\mathrm{CO}_{2}$ as a cushion gas may also arise as a way of getting additional benefit from a depleted gas reservoir where CSEGR has already been carried out.

Acknowledgments

This work was supported by the Assistant Secretary for Fossil Energy, Office of Coal and Power Systems through the National Energy Technology Laboratory, and by Lawrence Berkeley National Laboratory under Department of Energy Contract No. DE-AC0376SF00098. I thank Karsten Pruess, Marcelo Lippmann, and Tad Patzek (LBNL) for helpful comments and reviews.

\section{References}

Carrière, J.F., G. Fasanino, and M.R. Tek, Mixing in underground storage reservoirs, Society of Petroleum Engineers, SPE-14202, 9-12, 1985.

Department of Energy (U.S. DOE), Economic feasibility of inert cushions in underground gas storage, DOE/FE/33008-1, September 1980. 
Katz, D.L., and M.R. Tek, Overview of underground storage of natural gas, Jour. Petrol. Tech. 943, June 1981.

Laille, J-P., C. Coulomb, and M.R. Tek, Underground storage in Cerville-Velaine, France: A case history in conversion and inert gas injection as cushion substitute, Society of Petroleum Engineers, SPE-15588, 1986.

Laille, J-P., J-E. Molinard, J-E., and A. Wents, Inert gas injection as part of the cushion of the underground storage of Saint-Clair-Sur-Epte, France, Society of Petroleum Engineers, SPE-17740, 343-352, 1988.

Magee, J.W., J.A. Howley, J.F. Ely, A predictive model for the thermophysical properties of carbon dioxide rich mixtures, Research Report RR-136, Gas Processors Assoc., Tulsa OK (1994) 35 pp.

Mamora, D.D., and J.G. Seo, Enhanced recovery by carbon dioxide sequestration in depleted gas reservoirs, Soc. Petrol. Eng. SPE-77347, SPE Annual Tech. Conf. and Exhibition, San Antonio TX, 29 Sept.-2 Oct. 2002.

Misra, B.R., S.E. Foh, Y.A. Shikari, R.M. Berry, and F. Labaune, The use of inert base gas in underground natural gas storage, Society of Petroleum Engineers, SPE-17741, 1988. 
NIST (National Institute of Science and Technology), "NIST Database 14 Mixture Property Database, version 9.08," U.S. Department of Commerce (Oct. 1992).

Oldenburg, C.M., S.M. Benson, and K. Pruess, Process modeling of $\mathrm{CO}_{2}$ injection into natural gas reservoirs for carbon sequestration and enhanced gas recovery, Energy \& Fuels, 15, 293-298, 2001.

Oldenburg, C.M. and S.M. Benson, $\mathrm{CO}_{2}$ injection for enhanced gas production and carbon sequestration, Society of Petroleum Engineers, SPE-74367, February 2002.

Pruess, K., C. Oldenburg, G. Moridis, TOUGH2 User's Guide, Version 2.0, Lawrence Berkeley National Laboratory Report LBNL-43134, November 1999.

Tobin, J., and J. Thompson, Natural gas storage in the United States in 2001: A current assessment and near-term outlook, U.S. DOE Energy Information Administration, 2001.

Walker, C.J., and R.V. Huff, Feasibility of inert-gas cushions in gas storages, Bureau of Mines Report of Investigations 6534, U.S. Dept. of the Interior, 1964, 25 pp.

Yu, D., K. Jackson, and T.C. Harmon, Dispersion and diffusion in porous media under supercritical conditions, Chem. Eng. Sci., 54, 357-367, 1999. 
Figures

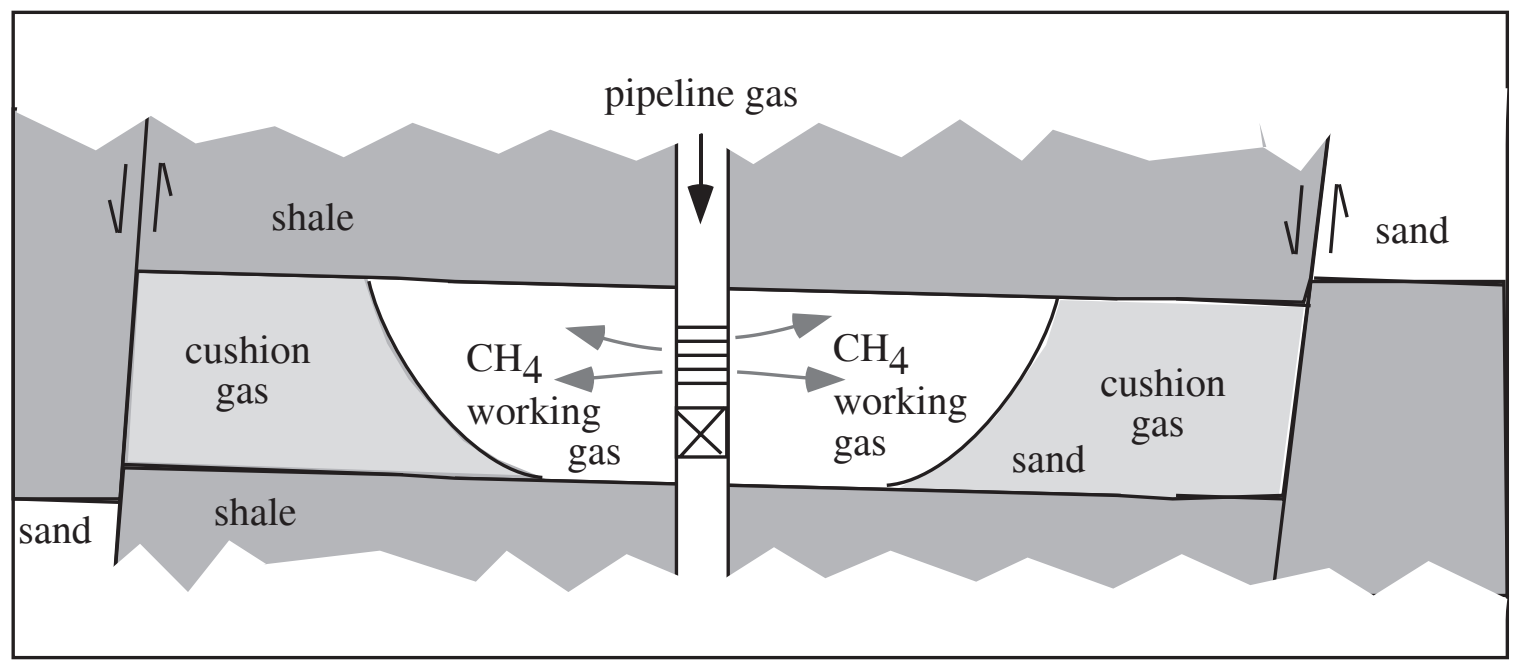

Figure 1. Idealized single-well natural gas storage schematic showing working gas and cushion gas.

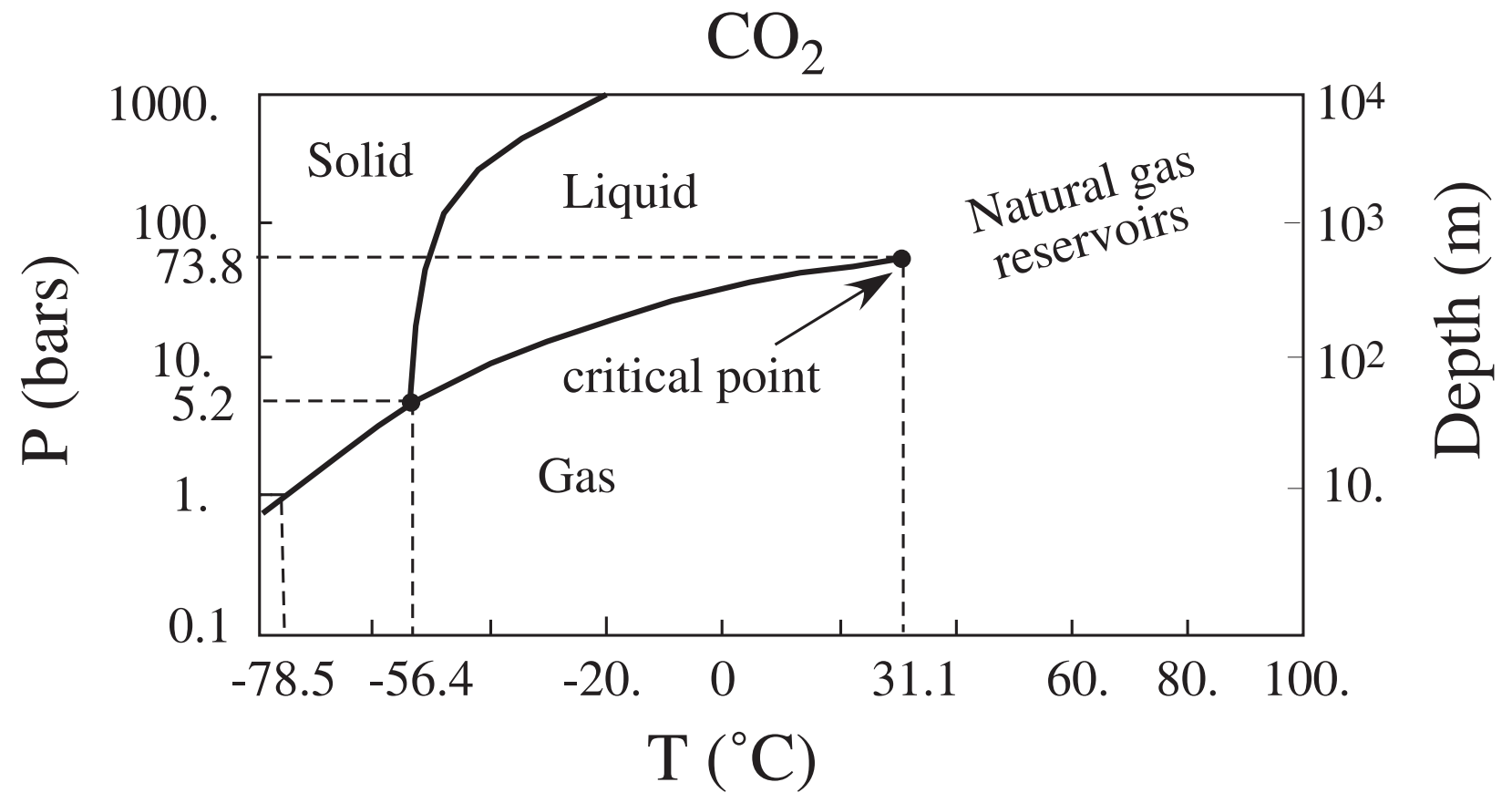

Figure 2. Semi-log plot phase diagram for $\mathrm{CO}_{2}$ showing $\mathrm{CO}_{2}$ will be supercritical in typical natural gas reservoirs. 


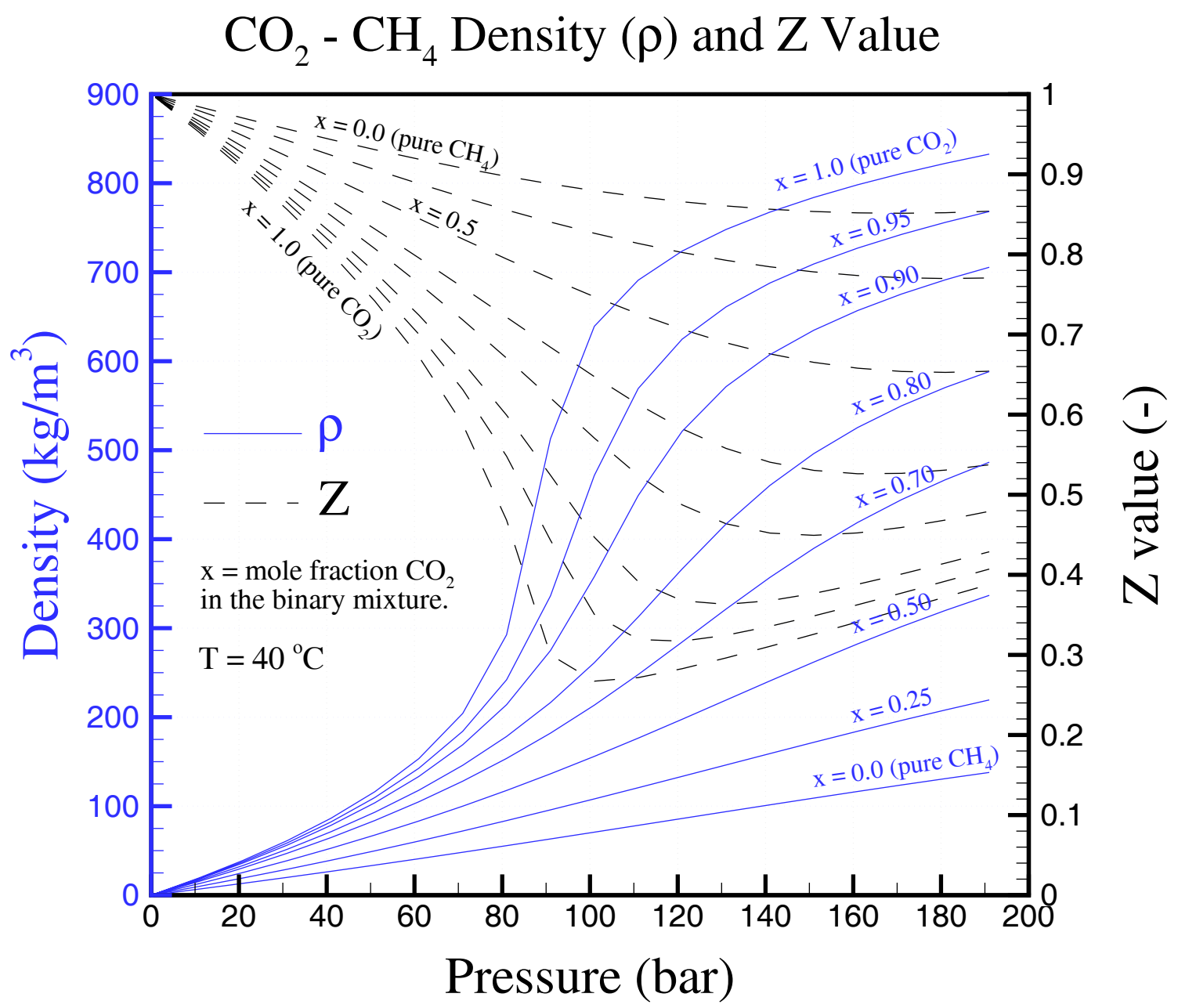

Figure. 3. Density and $\mathrm{Z}$ value of $\mathrm{CO}_{2}-\mathrm{CH}_{4}$ mixtures at $T=40{ }^{\circ} \mathrm{C}$ (source: Magee et al., 1994; NIST, 1992). 


\section{Density and Viscosity of $\mathrm{CO}_{2}-\mathrm{CH}_{4}$ Mixtures}

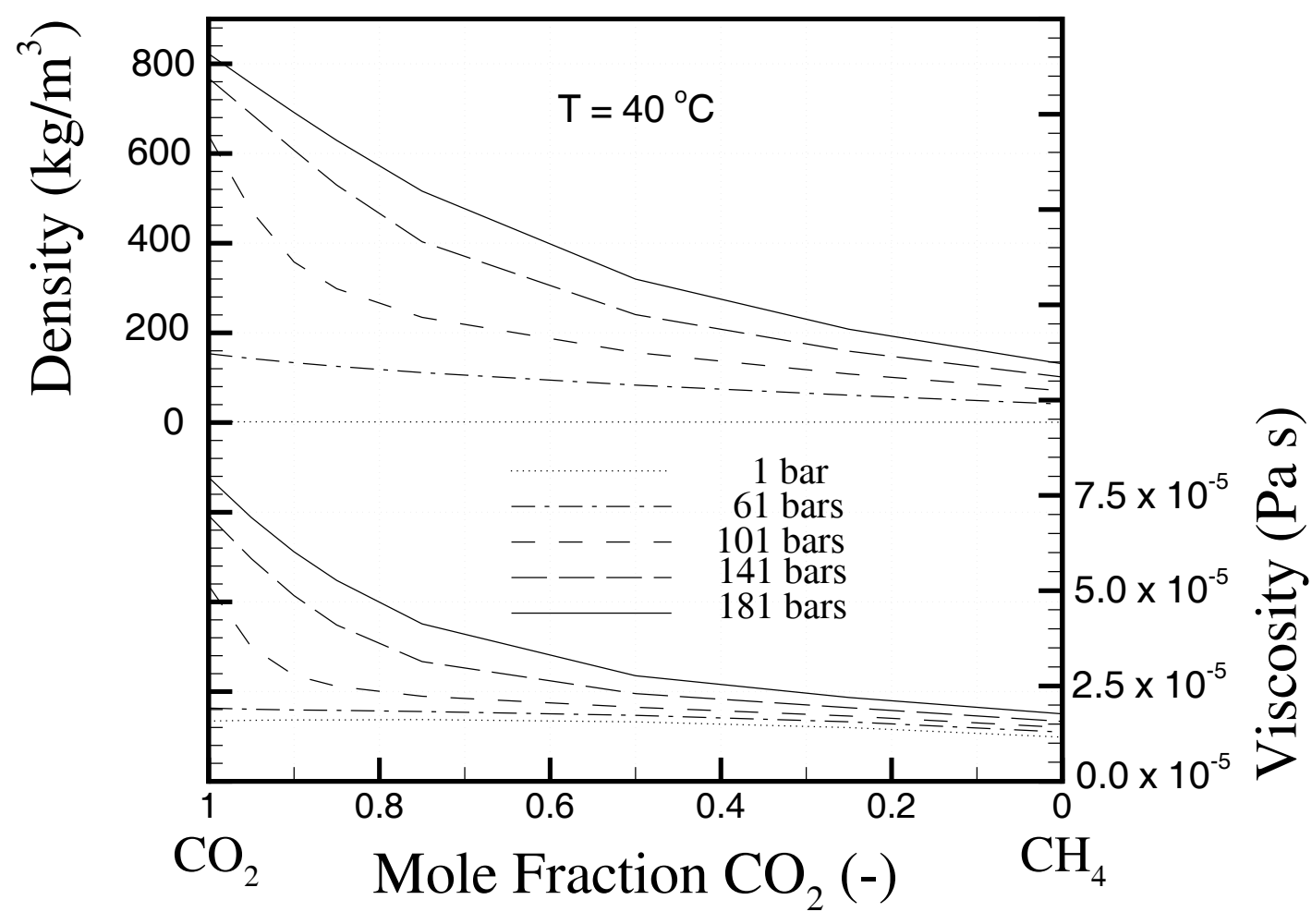

Figure 4. Density and viscosity of $\mathrm{CO}_{2}-\mathrm{CH}_{4}$ mixtures at several relevant pressures at $T=$ $40{ }^{\circ} \mathrm{C}$ (source: Magee et al., 1994; NIST, 1992). 


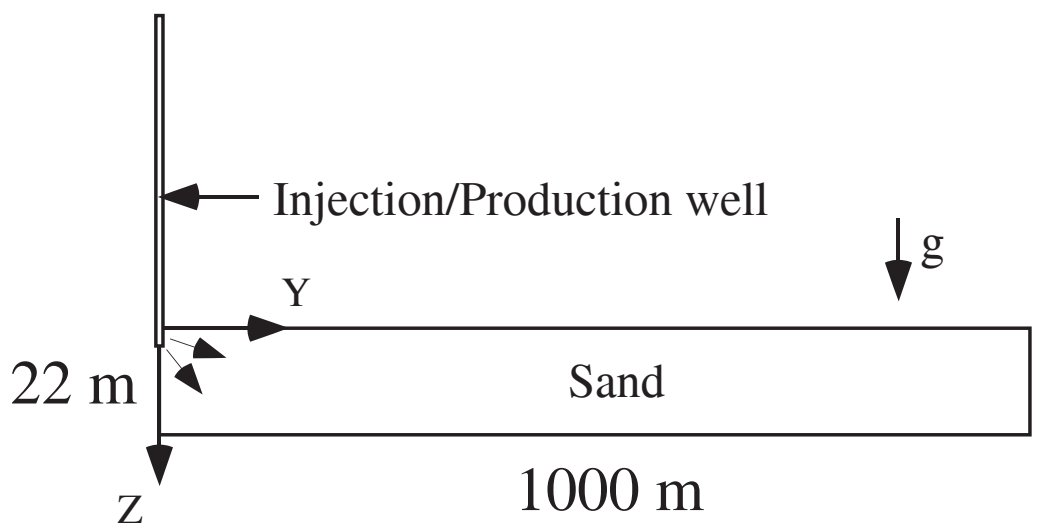

Figure 5. Schematic of two-dimensional simulation domain. 

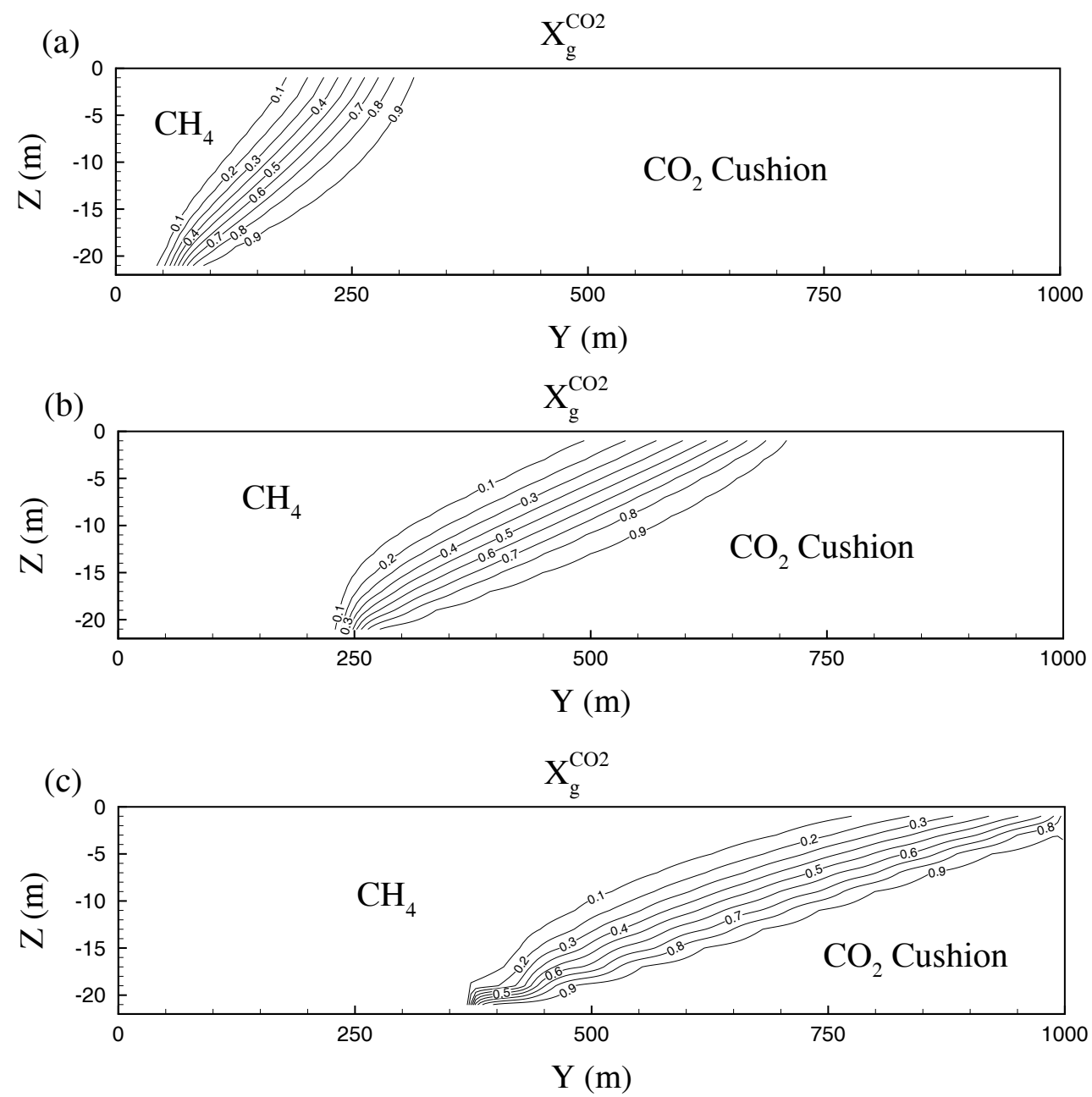

Figure 6. $\mathrm{CO}_{2}$ mass fraction in the gas after 30, 90, and 180 days of injection. 

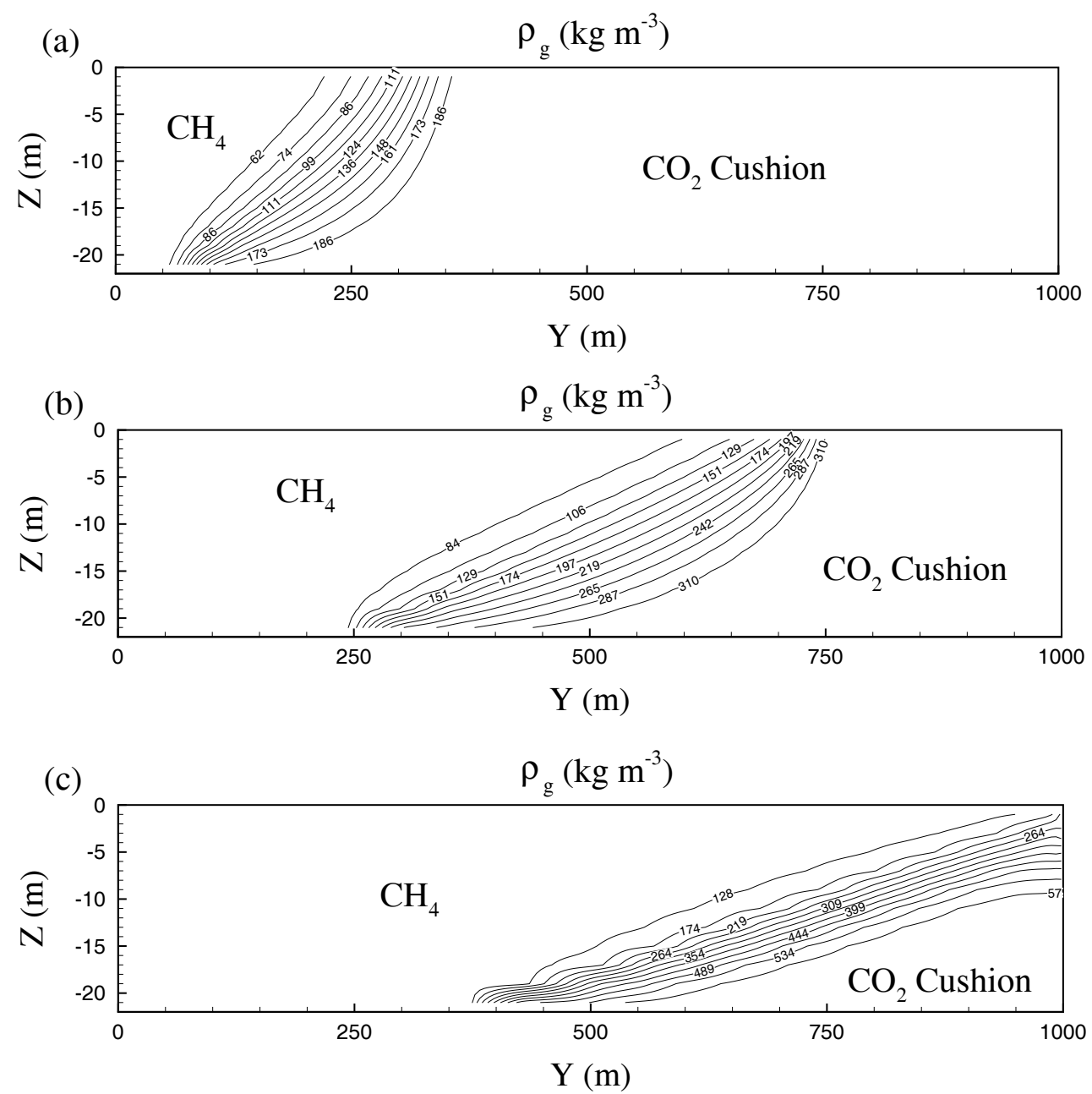

Figure 7. Gas density after 30, 90, and 180 days of injection. 


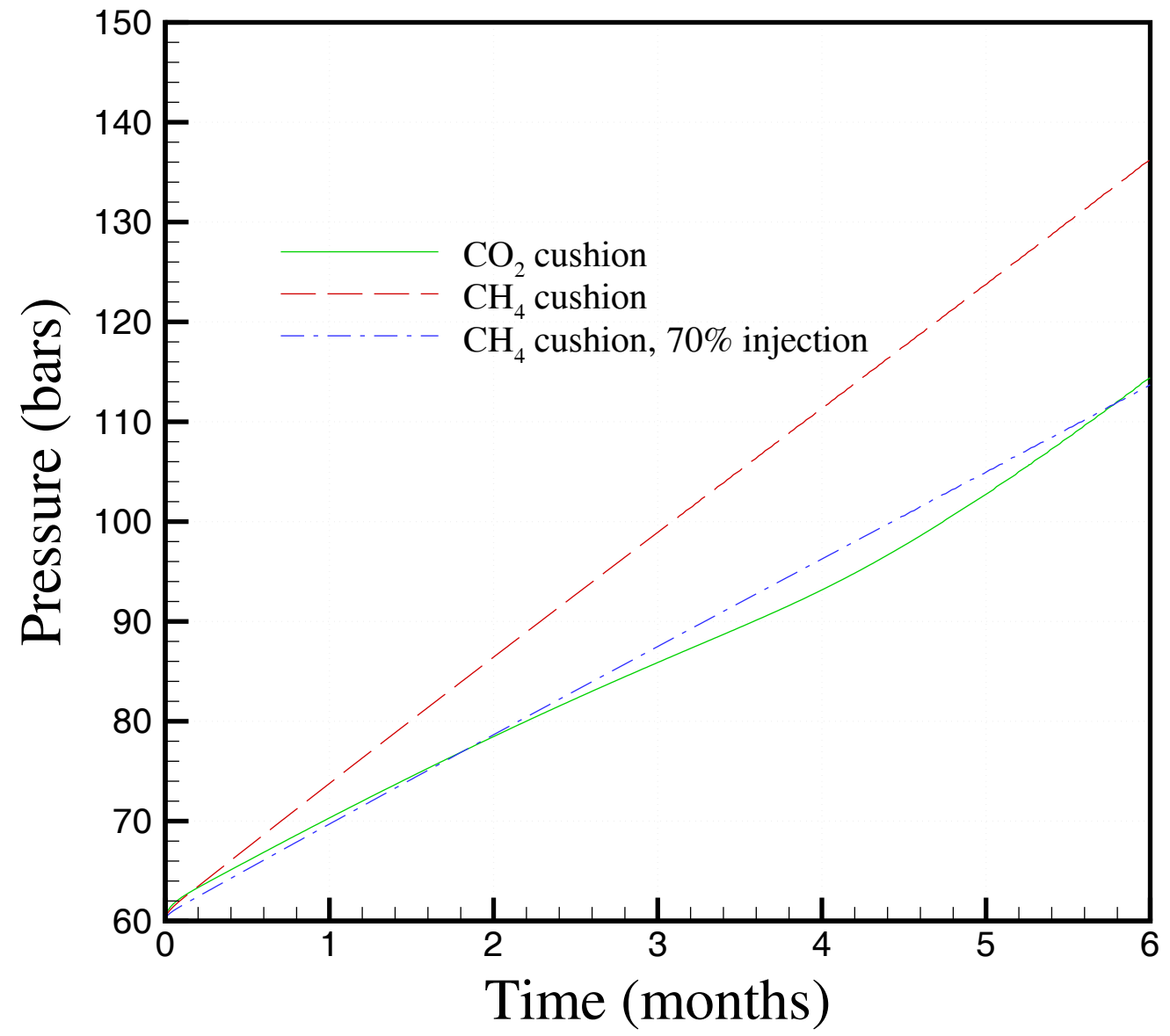

Figure 8. Pressure as a function of time for constant injection rate using $\mathrm{CO}_{2}$ and native $\mathrm{CH}_{4}$ as cushion gas. 

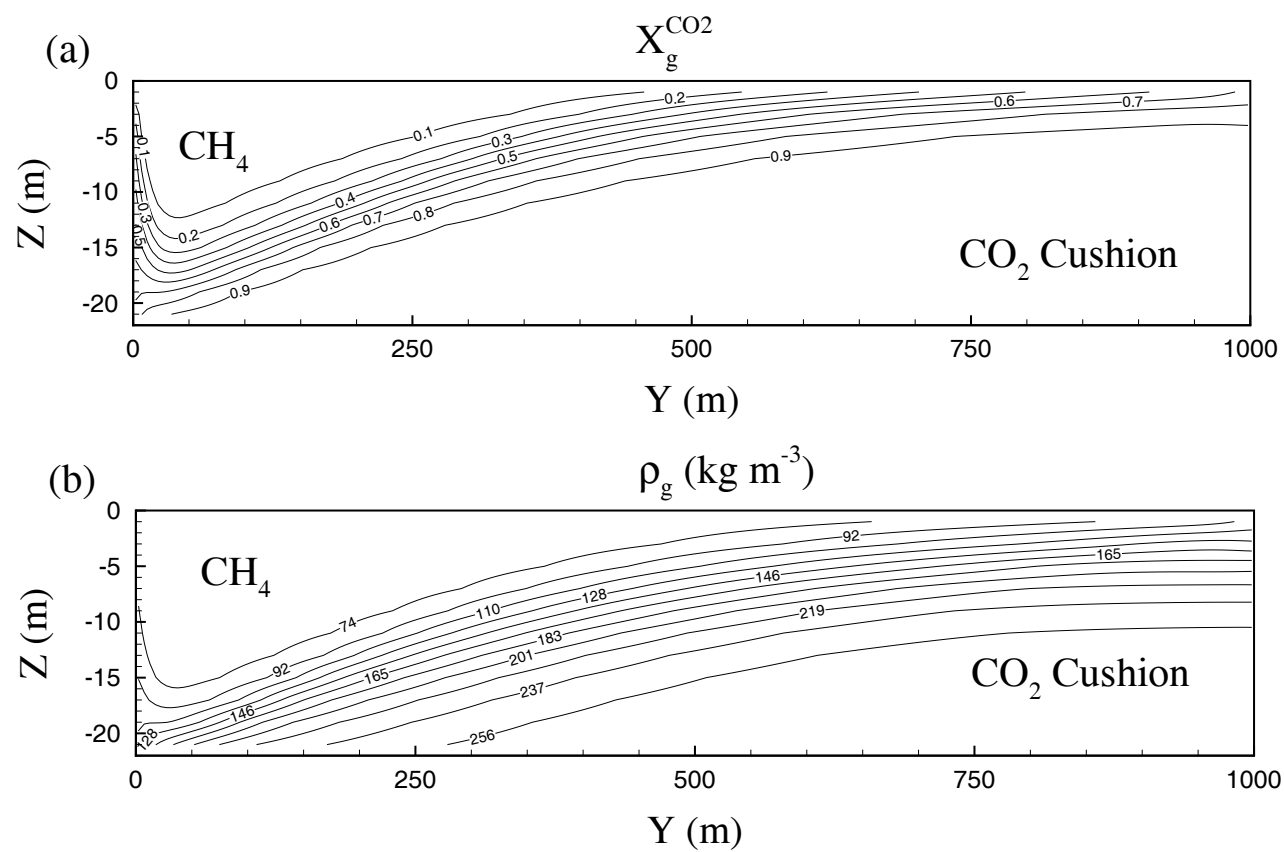

Figure 9. Mass fraction of $\mathrm{CO}_{2}$ in the gas and density after 120 days of gas production. 